\title{
Jean- Marc Civardi, La querelle du 'Cid' (1637-38)
}

\section{Daniela Dalla Valle}

\section{(2) OpenEdition}

\section{Journals}

\section{Edizione digitale}

URL: http://journals.openedition.org/studifrancesi/34613

DOI: 10.4000/studifrancesi.34613

ISSN: 2427-5856

\section{Editore}

Rosenberg \& Sellier

\section{Edizione cartacea}

Data di pubblicazione: 1 novembre 2005

Paginazione: 410

ISSN: 0039-2944

\section{Notizia bibliografica digitale}

Daniela Dalla Valle, «Jean- Marc Civardi, La querelle du 'Cid' (1637-38)», Studi Francesi [Online], 146 (XLIX | II) | 2005, online dal 30 novembre 2015, consultato il 18 avril 2021. URL: http:// journals.openedition.org/studifrancesi/34613 ; DOI: https://doi.org/10.4000/studifrancesi.34613

\section{Questo documento è stato generato automaticamente il 18 avril 2021.}

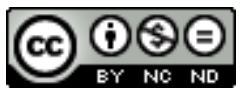

Studi Francesi è distribuita con Licenza Creative Commons Attribuzione - Non commerciale - Non opere derivate 4.0 Internazionale. 


\section{Jean- Marc Civardi, La querelle du 'Cid' (1637-38)}

Daniela Dalla Valle 


\section{NOTIZIA}

JEAN-MARC CIVARDI, La querelle du 'Cid' (1637-38). Edition critique intégrale, Paris, Honoré Champion, 2004, pp. 1216.

1 L'imponente volume pubblicato da Champion riprende, rielabora ed introduce nella critica moderna il problema della «querelle du Cid», per cui eravamo ancora debitori all'edizione di Armand Gasté, vecchia di oltre un secolo. In questo caso si tratta della pubblicazione di una tesi recente, e non possiamo che rallegrarcene, perché essa ci ripropone - sotto prospettive nuove - un momento così importante della nascita e della codificazione del teatro francese secentesco.

Prima di dare l'edizione critica delle pièces e dei pamphlets che costituiscono la querelle, il volume articola il suo discorso introduttivo in tre parti (più di 250 pagine, contro le poco più di 50 di Gasté). Si passa dalla Présentation de la querelle, a Les enjeux de la querelle en 1637 e poi a Les enjeux modernes de la querelle (quali erano, dunque, i problemi teorici precedenti la querelle, e quali ne furono le conseguenze). Poi segue l'edizione di tutti i libelles già pubblicati da Gasté, a cui si aggiunge l'Anatomie du Cid (che esiste soltanto manoscritto alla B.N. de France). Ogni libelle è presentato con numerose note e con un'introduzione puntuale ed estremamente ricca, che precisa, definisce, puntualizza l'argomentazione storico-critica, affrontando una serie di problemi interessanti che non possono - ovviamente - essere ripresi in una scheda. Molto ricca è la bibliografia, mentre un glossario elenca i termini che sono stati oggetto, nel volume, di un'osservazione di vocabolario o di grammatica.

3 Il volume di Civardi, nuova rilettura della famosa querelle, è un'opera assolutamente essenziale nella biblioteca di un secentista. 